\title{
Endüstriyel Atık Geri Dönüşümünde Etkili Olan Karar Kriterlerinin BWM ile Değerlendirilmesi: Plastik, Cam ve Çelik Endüstrisinde Uygulama
}

\author{
Damla Çevik Aka ${ }^{1 *}$ \\ 1* Sakarya Üniversitesi, İşletme Enstitüsü, Üretim Yönetimi ve Pazarlama Anabilim Dalı, Sakarya, Türkiye, (ORCID: 0000-0001-9622-273X), \\ damlacevik@sakarya.edu.tr
}

(İlk Geliş Tarihi 29 Eylül 2021 ve Kabul Tarihi 12 Aralık 2021)

(DOI: 10.31590/ejosat.1001853)

\begin{abstract}
ATIF/REFERENCE: Çevik Aka, D. (2021). Endüstriyel Atık Geri Dönüşümünde Etkili Olan Karar Kriterlerinin BWM ile Değerlendirilmesi: Plastic, Cam ve Çelik Endüstrisinde Uygulama. Avrupa Bilim ve Teknoloji Dergisi, (31), 390-398.

$\ddot{\mathbf{O z}}$

Tüm dünyada üretim ve tüketime bağlı olarak birçok endüstride ortaya çıkan çevresel, sosyal ve ekonomik problemler ve endüstriler tarafından değişen beklentiler, firmaları sürdürülebilir iş uygulamalarına itmektedir. Çalışmada, firmaların dış kaynak kullanımı ile geri dönüşüm faaliyetlerini üretim süreçlerine dahil etme kararı vermesinde etkili olan kriterlerin önem derecelerinin belirlenmesi amaçlanmıştır. Ayrıca kriterlerin ağırlıkları plastik, cam ve çelik olmak üzere üç farklı sektör için ayrı olarak hesaplanarak, sektörel farklılıkların ve benzerliklerin ortaya koyulması istenmektedir. Mevcut literatürde aynı amaca ulaşacak farklı sektörlerdeki uygulamalara yer verilmemiş olması, araştırmanın özgün değerini ortaya koymaktadır. Çalışmada literatür taraması ve uzman görüşleri sonrasında ilgili kriterler: alternatif getiri, maliyet avantajı, istihdam, müşteri memnuniyeti, su tüketimi, enerji tüketimi ve sera gazı olarak belirlenmiş ve bu yedi kriterin ağırlıklandırmasında her sektörden ayrı ayrı altı kişi olacak şekilde toplamda 18 kişiyle çalışılmıştır. Problem çözümünde birden fazla kriterin olması ve her kritere çalışmayla tutarlı olacak şekilde ağırlık verilme ihtiyacı sebebiyle "En İyi En Kötü Yöntem (Best Worst Method)" kullanılmıştır.
\end{abstract}

\section{Evaluation of Effective Decision Criteria in Industrial Waste Recycling with BWM: An Application in the Plastic, Glass and Steel Industries}

\begin{abstract}
Environmental, social and economic problems arising in many industries due to production and consumption all over the world and changing expectations by industries encourage companies to sustainable business practices. In the study, it's aimed to determine the importance levels of the criteria that are effective in the decision of including the recycling activities to the production processes together with the outsourcing of the companies. In addition, the weights of the criteria for three different sectors, plastic, glass and steel, are calculated separately, and sectoral differences and similarities are required to be revealed. The fact that applications in different sectors that will achieve the same goal are not included in the existing literature reveals the original value of the research. In the study, after the literature review and expert opinions, the relevant criteria were determined as: alternative return, cost advantage, employment, customer satisfaction, water consumption, energy consumption and greenhouse gas, and six experts from each sector were evaluated separately in the weighting of these seven criteria. "Best Worst Method" was used in problem solving because of the need to have more than one criterion and to give weight to each criterion in a way that is consistent with the study.
\end{abstract}

Keywords: Sustainability, Recycling, Resource Recovery, Multi-Criteria Decision Making, Best Worst Method.

*Sorumlu Yazar: damlacevik@ sakarya.edu.tr 


\section{Giriş}

İnsanların doğaya, doğada bulunan kaynaklara, üretim süreçlerine veya tüketime karşı bilinçsizce hareket etmesi beraberinde birçok problemin doğmasina neden olmuştur. Üretim girdi kaynaklarının gereksiz tüketimi ve istenmeyen çıktıların fazla üretim durumları endüstriyel sistemleri ekolojik olarak sürdürülemez hale getirmektedir (Gatimbu vd., 2018). Biyoçeşitlilik kaybı, yerel hava, su ve toprak kirliliği, doğal kaynakların azalması, kaynakların tükenmeye başlaması ve aşırı alan kullanımı gibi çevresel sorunlar, dünyanın yaşam sistemlerini tehdit etmeye başlamıştır. Çevresel açıdan büyüyen problemler ile beraber sosyal açıdan da yaşanan sıkıntılar toplumların endişelerini arttırmaktadır. İşsizlik oranlarının yükselmesi, çalışma koşullarındaki dengesizlik, çalışma yerlerinin her geçen gün kötüleşmesi ve toplumun belirli tabakalarında artan eşitsizlik önemli konulardan olmuştur. Çevresel ve sosyal etkilerin yanı sıra ekonomik durumlar da firmaları her geçen gün sürdürülebilir olmaya itmektedir. Karşılaşılan tedarik zinciri problemleri, kuralsızlaşan piyasalar ve adil olmayan rekabetler firmalarda finansal istikrarsızlığa neden olmaktadır. Yaşanan bu durumlar tüm dünyanın büyük bir farkındalık sürecine girmesinde etkili olmuş ve kurumların sürdürülebilir olmak için önemli adımlar atmasını sağlamıştır.

Sürdürülebilirlik kavramı, birçok farklı disiplin içinde kullanılması sebebiyle farklı tanımlarda ifade edilen bir kavram olmuştur. Sürdürülebilirlik, kaynakların yok olması, enerji maliyetlerinde yaşanan dalgalanmalar, çevresel kirlilik ve atıklardan doğan çevresel riskleri azaltma ihtiyacıyla ortaya çıkan (Shrivastava, 1995) bir çabadır. McMichael vd. (2003) tarafından kavram, değiştirilemez mal ve hizmetlerin arzını devam ettirerek, güvenlik, refah ve sağlık konularını optimize etmeyi amaçlayan bir dönüşüm olarak tanımlanmıştır. Sürdürülebilirlik, enerji tüketiminin en aza indirilmesine ve atıkların verimli kullanılmasına teşvik eden organizasyonel uygulamalar bütünü olarak da ifade edilebilmektedir (Eltayeb \& Zailani, 2010). Kısaca sürdürülebilirlik kavramı, çevresel, ekonomik ve sosyal olmak üzere üç farklı boyut üzerinden incelenmektedir. 1990'l y ylların sonlarında, iyi bir ekonomist olan J. Elkington tarafından üçlü alt çizgi (TBL) kavramı geliştirilmiş ve bu üç boyutun en azından temel seviyeye ulaşmadan boyutların ayrı olarak istenen seviyeye getirilemeyeceğini ifade etmiştir. TBL olgusu, ekonomik boyutlara sosyal ve çevresel boyutların dahil edildiği başarılı bir performans ölçme aracı olarak görülmektedir. Sürdürülebilirliğin üç boyutunun eş zamanlı değerlendirilmesi önemlidir. Sürdürülebilir uygulamalardaki birçok belirsizliğe rağmen, esas bileşenleri tanımlamak, bileşenler arası ilişkileri ortaya koymak, sistemi bütünsel olarak değerlendirmek gereklidir (Harris, 2000).

$\mathrm{Bu}$ çalışmada da firmaların, sürdürülebilir uygulama alanlarından olan geri dönüşüm faaliyet kararlarını vermelerinde etkili olan hem ekonomik hem çevresel hem de sosyal boyutların önce belirlenmesi, ardından ağırlıklandırılması amaçlanmaktadır. Farklı endüstri kollarında sonuçların değişeceği beklentisiyle, üç farklı sektörden uzmanla görüşmeler yapılarak verilen kararda belirleyici olan sürdürülebilirliğin üç boyutunun etkisi de ortaya koyulacaktır.

\section{Kavramsal Çerçeve}

\subsection{Sürdürülebilirlik Boyutları}

Firmaların sosyal açıdan sorumluluk sahibi olması, ekonomik açıdan rekabet edebilmesi ve çevresel açıdan ekosistemi koruyacak şekilde davranması sürdürülebilir bir dünya için önemlidir. Sürdürülebilirliğin üç boyutundan biri olan çevresel boyutun yeri ayrıca önemlidir. İşletmelerin üretim sistemlerindeki her aşamalı süreçlerinin çevreye verdiği zararı minimum seviyeye dönüştürmesi ve firma stratejilerine çevresel bileşenleri dahil etmesi gerekmektedir (Yacob vd.,2019). Çevresel sürdürülebilirlik, çevre ve insan ilişkilerinde ekolojinin en doğal şekliyle korunmasını sağlayarak, çevreye verilen zararların onarılmasını sağlayan faaliyetler bütünüdür (Goodland, 1995). Çevresel sürdürülebilirlik, gelecek nesillerin ekonomik, sosyal ve çevresel ihtiyaçlarını karşılayabilecek şekilde ekoloji ile uyumlu koşulların yaratılması ve sürdürülmesidir (U.S Department of Energy, 2020). Bir başka açıdan kavram, ekosistemlere zarar vermeyecek şekilde insan ihtiyaçlarının karşılanması için benimsenen yaklaşımdır.

Çevresel sürdürülebilirlik stratejilerinin temelinde, k1t kaynaklar ile hem günümüz neslinin hem de gelecek neslin ihtiyaçlarının karşılanarak bu kaynakların devamlılığının sağlanması yer almaktadır. $\mathrm{Bu}$ sebeple doğal kaynakların tüketilme hızının yenilenme hızından küçük olması istenmektedir (Küçük \& Güneş, 2013). Beklenilen amacı gerçekleştirecek birçok farklı çevresel uygulamalar ve politikalar geliştirilmektedir. Erol \& Özmen (2008) tarafından yapılan bir çalışmada çevresel sürdürülebilirliği geliştirecek uygulamaların sonucunda su kullanımı, enerji tüketimi, yakıt tüketimi, atık üretimi, geri dönüşüm işlemleri, çevresel kirlilik, gürültü ve arazi kullanım konularından avantaj elde edilebileceği vurgulanmaktadır. Çevre stratejilerden birçoğu da atmosferdeki 1sıl dengeyi sağlayan sera gazı salınımları ile ilgilidir. Enerji tüketimin, bilinçsiz kaynak kullanımın, yanlış üretim teknolojilerin, ulaşım kaynaklarının gereksiz kullanımların sonucunda topluma ve çevreye zarar veren miktarlarda gaz salınımı olmaktadır.

Literatür incelemesine bakıldığında çevresel sürdürülebilirlik boyutları farklı araştırmacılar tarafından farklı açılardan ele alınmıştır. Rao (2002) katı atıklar, su tüketim miktarları, hava emisyon yayılımı üzerinden; Szekely \& Knirsch (2005) emisyon miktarı ve enerji tüketimi üzerinden; Vachon \& Klassen (2008) katı atık miktarı, su tüketim oranları ve gaz emisyonu açısından; Glavas \& Mish (2015) enerji tüketim miktarı, tehlikeli madde kullanımı ve atık yönetimi açısından konuyu değerlendirmişlerdir. Son yıllardaki çalışmalardaki temel boyutlar da eko tasarım, yeşil paketleme, temiz üretim ve iş birliği düzeyi (kaynak kurtarma) (Ni \& Sun, 2019); gaz emisyonu, ürün geri dönüşüm oranı, katı atık önleme, zararlı madde tüketimi, çevre kazaları ve çevresel girişimler (Dubey vd., 2020); ürün geri dönüşüm oranı, kaynak geri kazanım ve bertaraf oranı (Chaudhary \& Vrat, 2020); emisyon miktarı, enerji tüketimi ve atık miktarı (Spallini vd., 2021); emisyon miktarı, yeşil paketleme ve yeşil lojistik üzerine gerçekleşmektedir (Haryanti \& Subriadi, 2021).

Ekonomik sürdürülebilirlik ise organizasyonların karlılık gibi finansal durumlarına öncelik vererek ekonomik performanslarını geliştirme ve pazardaki sahip oldukları konumu koruma veya geliştirme amaciyla yürüttüğü stratejilerdir (Kurnaz \& Kestane, 2016). Ekonomik sürdürülebilirliğin amac1 kurumların çevresel etkileri ile ekonomik durumu arasındaki 
dengeyi sağlamaktır. Çevresel sürdürülebilirlik ile eş zamanlı yapılan ekonomik sürdürülebilirlik stratejilerinin uzun dönemde organizasyonlara fayda sağlaması beklenmektedir. Ekonomik sürdürülebilirliği sağlayan işletmeler, garanti nakit akışları ve kârlılığı olan işletmeler olarak görülmektedir. (Njoroge vd., 2019). Elliott (2005), ekonomik açıdan sürdürülebilir olmak için uzun dönemde istikrarlı bir ekonomiye sahip olmak gerektiğini ifade etmiş ve ayrıca toplam sermayenin azalmaması ve kıt kaynaklardan maksimum faydanın sağlanmasını, ekonomik sürdürülebilirliği arttıran eylemlerden görmüştür.

Literatürde farklı boyutlar üzerinden incelenen ekonomik sürdürülebilirlik boyutunu Tsai \& Hung (2009) atıkların bertaraf maliyeti ve yeniden işlem maliyeti, Ameer \& Othman (2012) aktif getiri, vergilendirme öncesi kar ve nakit akış1; Santos vd. (2013). öz kaynak verimliliği; Tajbakhsh \& Hassini (2015) firma imajı, kar, yatırım oranı ve yeni müşteri elde etme oranı üzerinden incelemiştir. Ayrıca $\mathrm{Hu}$ vd. (2019) ekonomik sürdürülebilirliği hurda malzeme satış miktarları, sermaye fazlası ekipman satışı, geri dönüşüm sistem yatırımları ve stok fiyatları; Dubey vd. (2020) satın alma maliyetleri, enerji maliyeti, atık maliyetleri, geri kazanım maliyetleri ve vergi; Abdelaziz vd. (2020) ciro, büyüme oranı, kaynak kullanımı ve talep; Haryanti \& Subriadi (2021) ekonomik büyüme, satış miktarı (karlılık), vergi ve verimlilik; Spallini vd. (2021) risk yönetimi, ekonomik değer (karlılık) ve tedarikçilere yapılan harcama (yatırım) boyutları üzerinden değerlendirmiştir.

Sürdürülebilirliğin üçüncü boyutu olan sosyal sürdürülebilirliğin odağında insan vardır. Sosyal sürdürülebilirlik, insanların yaşadığı ve çalıştığ duyduğu ihtiyaçları tespit ederek bu doğrultuda refahı teşvik eden başarılı ortamlar yaratma sürecidir (Woodcraft, 2015). Sosyal sürdürülebilirlik, insanların temel ihtiyaçlarının yanı sıra sağlık, eğitim, ulaşım, siyaset, adalet gibi konularda da duyduğu ihtiyaçları karşılamaya yönelmektedir. Morelli (2011) sosyal sürdürülebilirliği, eşitlik, yerel düzeyde siyasi haklar, toplum olabilme durumu, farklı değerlerdeki insanlar arası ilişkiler, sosyal haklara yönelik bilinç, insan ihtiyaçlarının karşılanabilme durumları üzerinden anlatmıştır. Kavram, toplumun herhangi bir kesimini ayırmadan toplum bütünlüğünü sağlama amacıyla ortak hedeflere ulaşabilmesini sağlamaktadır. Sosyal sürdürülebilirlik olgusu içinde önemli olan insanların 'eşit haklara' sahip olması gerekliliğidir. $\mathrm{Bu}$ sayede toplumda sosyal yönden dengeli bir ortamın yaratılabilmektedir.

Sosyal sürdürülebilirlik uygulamaları literatürde farklı açılardan değerlendirilmektedir. Sosyal sürdürülebilirliği Singh vd., (2007) çalışan sağlığı ve kaza oranları, Hubbard (2009) topluma ayrılan yatırım miktarları, Ahi \& Searcy (2015) müşteri memnuniyeti, gönüllülük ve paydaşların katılımı; Lenort vd., (2017) çalışan devir hızı, sağlık ve güvenlik, eğitim; Govindan vd. (2019) insan kaynakları faaliyetleri, paydaş katılımı, sağlık, eğitim, eşitlik ve iş olanakları; Dubey vd. (2020) cinsiyet eşitliği, çocuk çalışan sayısı, fakirlik oranı, organizasyon tarafından verilen yemek içeriği, sunulan güvenli içme tesisi, sağlık hizmeti, konut desteği ve ulaşım olanakları; Spallini vd. (2021) istihdam, eğitim, eşitlik, müşteri gizliliği ve müşteri memnuniyeti; Haryanti \& Subriadi (2021) ise müşteri memnuniyeti, istihdam ve yönetime bağlılık boyutları üzerinden değerlendirmiştir.

\subsection{Geri Dönüşüm Sistemi}

Firmaların sürdürülebilir stratejilere olan yaklaşım konularından biri de atık yönetim üzerine gerçekleşmektedir. Atık üretimi farklı içeriklerde veya özelliklerde olmasına rağmen tüm dünyanın kritik problemlerden biri haline gelmiştir. Atık miktarının tüm dünyada gelecek 25 yıl içinde 3.5 milyar ton olması beklenmektedir (Kaza vd., 2018). Çevreye olan zararı minimum seviyeye düşürmek ve çevresel açıdan sürdürülebilir olmak için işletmeler tarafından uygulanan faaliyetlerden biri de atıkları geri dönüştürmektir. Geri dönüşüm sistemi, atık malzemelerin finansal, çevresel ve toplumsal kaynaklara dönüştürülmesidir (US Environmental Protection Agency, 2012). Özellikle büyük endüstrilerde üretime bağlı olarak üretilen atıkların başarılı yönetimi çevresel katkı sağlamanın yanında firmaya ekonomik açıdan da fayda yaratan bir durumdur. Ayrıca çevreyi korumaya yönelen atık yönetim uygulamalarının toplum üzerine faydası da büyüktür. Doğru yönetilmeyen katı atık yönetim sistemleri su-hava kirliliği, bu bölgelerde sinek vs. gibi hayvanlardaki artış, sera gazı yayılımları, hava kirliliğinden doğan sorunlar, atıkların sebep olduğu yangınlar ve atık alanlarındaki erozyon gibi olaylara sebep olmaktadır (Theisen, 2000).

İşletmeler geri dönüşüm sistemleri ile atık bertarafı, kaynakların korunması, depolama alanlarının ömrü, işletme maliyetleri gibi konularda avantaj sağlamaktadır (Moh \& Manaf, 2014). Atık ürün gruplarının tekrar geri kazandırılması ile firmalar hammadde, malzeme gibi maliyetlerde tasarruf elde ederken ekonomik açıdan faydalı durum ortaya çıkmaktadır. Geri dönüşüm işlemlerinin çevreye sağladığı faydalardan biri sera gazı salınımları üzerinedir. Atmosferdeki 1sıl dengeyi düzenleyen sera gazları, üretim-tüketim artışına, atıkların kontrolsüzce yakılmasına, enerji tüketimlerine, tarım faaliyetlerine bağlı olarak kontrolsüz bir şekilde artmaya başlamış ve toplum sağlığını da olumsuz etkilemektedir. Kontrollü yapılan geri dönüşüm işlemlerinin atıkların yakılmasına (imhasına) nazaran sera gazı salınımını sınırladığ ifade edilebilir. Diğer bir açıdan kaynak geri kazanım faaliyetleri aynı malzeme gruplarını birincil üretimle üretmekle karşılaştırıldığında enerji, yakıt, su miktarlarında da avantajlı olduğu bilinmektedir. Bu avantajlar firmaları sürdürülebilirliğe yaklaştırması açısından geri dönüşüm işlemlerinin gerekliliğini ortaya koymaktadır.

Geri dönüşüm işlemlerinin yer aldığı atık yönetimi, farklı endüstriler veya farklı ürün grupları içinde çeşitlilik gösterebilmektedir. Geri dönüşüm işlemlerinde önemli olan ürün gruplarından biri plastiklerdir. Plastik atıklardaki artış, özellikle son yıllarda gelişmiş ve gelişmekte olan ülkelerde tedirginlik yaratmaktadır. Sürdürülebilir plastik endüstrisi için plastiklerin geri kazanımı birincil adım olarak görülmektedir (Hopewell vd., 2009). Birçok teknolojinin gelişmesi ile beraber plastik atıkların geri dönüşümü ve geri kazanımı sürdürülebilirliğin gelişmesinde etkili olmuştur. Plastik geri dönüşümü ile beraber saf plastiğin üretilmesinin yerine üretim maliyetlerinde azalma, depolama ve atık yönetim maliyetlerinde avantaj elde etme, enerji ve doğal kaynakları koruma, işsiz ve yoksullar için istihdam sağlama alanlarında katkı sağlamaktadır (Gregory \& Kirchain, 2008). Wang vd., (2016)'nin çalışmasında da plastiklerin geri dönüşüm süreçleri sonucunda enerji, malzeme, maliyet ve zaman açısından tasarruf elde edileceğine yer verilmiştir. Plastiklerin tekrar malzeme olarak geri kazanılması, doğal kaynakların aşırı 
kullanımını azaltarak özellikle çevresel ve ekonomik açıdan büyük katkı sağlamaktadır.

Geri dönüşümde değerlenen ürün gruplarından bir diğeri camlardır. Camların biyolojik olarak parçalanamaması sebebiyle atık alanlarında çevre dostu bir çözüm sunmamaktadır (Meyer vd., 1996) bu sebeple cam ürünlerin geri kazanımı önemlidir. Cam atıklar, içeriğinde bulunan silisyum sayesinde geri dönüşümü kolay malzemelerdir. Birçok cam çeşidinin $\% 90$ oranlarında geri dönüştürüldüğü kabul edilmektedir. Bazı kaynaklarda ise camın asla kalite kaybına uğramadığını bu sebeple tamamının geri dönüştürülebilir olacağına yer verilmektedir (Sudharsan vd., 2018) ve bu özellik cam geri dönüşümünü cazip hale getirmektedir. Cam geri dönüşümünde bu malzemelerin birçok kez tekrar tekrar kullanabilmesi sürdürülebilirliğge olumlu etki yapan en temel özelliktir. Ayrıca geri dönüşüm faaliyetlerinde \%90-100 oranlarının yakalanması kaynak geri kazanımıyla beraber firmaların hammadde, tedarik, üretim maliyetlerinde de büyük faydalar sağlamaktadır. Cam geri dönüşümünde kullanılacak cam parçalarının hammaddesine göre daha düşük bir erime noktasına sahip olması (Alba Ingenieros, 2012), enerji tasarrufunda büyük avantaj sağlamaktadır (Larsen vd., 2009).

Bir diğer ürün grubu metal içerikli ürünlerdir. Metal atıkların birçoğu endüstriyel atık sınıfına girerek, alüminyum, bakır, çelik içeriğindeki ürünlere geri dönüşümde sıkça rastlanmaktadır. Plastik gibi malzemelerden farklı olarak kimyasal veya fiziksel formlarına bakılmadan metaller, bazı durumlarda ekonomik olmasa da sahip olduğu özelliklerin birçoğunu geri kazanabilir. Özellikle çeliklerin dünyada en çok kullanılan metal olması sebebiyle geri dönüştürülmeye duyulan ihtiyacı çok büyüktür. Nitekim çelikler, dünyada en fazla geri dönüştürülen malzemelerdir ve birçok çelik için kullanım ömürlerinin sonunda yüzde 100 geri dönüştürülebileceği kabul edilmektedir (World Steel Association, 2020). 2018 y1lında EPA tarafından araştırmada çelik endüstrisinin her yıl yaklaşı 12 milyon üründen geri dönüşüm yapıldığını ortaya çıkarmıştır (EPA, 2018). Çelik geri kazanım faaliyetleri hem ekonomik hem çevresel sürdürülebilirlik açısından avantajlıdır (Holappa, 2020). Çeliğin üstün sürdürülebilirlik performansı, yaşam ömrü boyunca çevreye vereceği zararı minimum seviyeye düşürebilmektedir. Çelik geri dönüşümünde ayrıca çeliklerin kalitesinde herhangi bir bozulmanın olmadığı bilinmektedir. Worldsteel (2020) tarafından 2020 yılında yapılan çalışmada, bir arabada bulunan tüm çelik malzemelerin geri dönüştürülmesi sonucunda, 300 galondan fazla benzin tüketmeye eşdeğer sera gazı emisyonlarının azalabileceği bilgisine ulaşılmıştır. Bir başka çalışmada ise enerji tasarrufuna vurgu yapılmış ve çelik bir gıda tenekesinin geri dönüştürülmesiyle 60 watt'lık bir ampulün dört saatten fazla yanması için gereken enerji kadar tasarruf yapıldığ 1 görülmüştür (EPA, 2018).

Farklı endüstriler, farklı ürün grupları için geri dönüşüm faaliyetleri yapılsa da, temelinde her bir faaliyet alanı sürdürülebilirliğe giden yolda işletmelere aynı amaçlarda destek sağlamaktadır. Böylesine büyük etkilere sahip olan geri dönüşüm faaliyetleri, işletmeler için birer firsat olarak görülmeye başlanmıştır. Ancak bu tesislerin kurulmasının büyük yatırımlar gerektirmesi sebebiyle firmalar atık olarak ayırdığ ürünlerin geri dönüşümünde dış kaynak kullanımına ihtiyaç duymaktadır. Fakat firmaların çeşitli sebeplerden endüstriyel atık (tehlikesiz) olarak ayırdığı ürünleri dış kaynak kullanarak geri dönüştürmek istemesinde birçok farklı kriterin varlığı ve bu kriterlerin her birinin karar üzerinde farklı etkileri söz e-ISSN: 2148-2683 konusudur. Literatürde işletmelerin dış kaynak kullanımı ile geri dönüşüm faaliyet kararlarına etki edecek kriterlerin belirlendiği ve sektörel olarak kriterlerin ağırlıklandırıldığı bir çalışmaya yer verilmemiştir. $\mathrm{Bu}$ çalışma, literatürdeki bu boşluğu dolduracak şekilde cam, çelik ve plastik olmak üzere konuyu üç farklı sektör üzerinde değerlendirecek ve olası sonuçları karşılaştıracaktır.

\section{Materyal ve Metot}

\subsection{Araştırma Tasarımı}

Çalışma, altı temel adımdan oluşmaktadır (Şekil 1):

Şekil 1. Araştırma Adımları

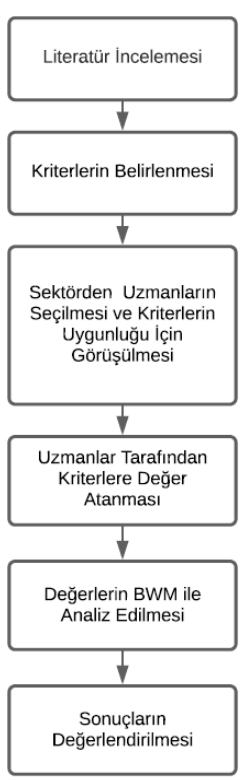

\subsection{Yöntem}

Çalışmada, Çok Kriterli Karar Verme (ÇKKV) yöntemlerinden biri olan BWM (Best-Worst Method) veya bir diğer adıyla en iyi en kötü yöntem kullanılmaktadır. Yöntem, 2015 yılında Razei tarafindan karar vericilerin verdiği cevaplarda daha tutarlı sonuçların elde edilmesi için oluşturulmuştur. Razei (2015) tarafindan geliştirilen yöntemin adımları şu şekildedir:

Adım 1. Tüm kriterler listelenir (C1, C2,..,Cn).

Adım 2. Karar verici(ler) tarafından $n$ adet kriterden en iyi ve en kötü olan kriterler belirlenir.

Adım 3. Karar verilen en iyi kriterin diğer kriterlere göre önem(tercih) durumu 1 ile 9 arasındaki sayılara göre belirlenir (Tablo 1). En iyi kritere göre oluşan vektör, $A_{B}=\left(a_{B 1}, a_{B 2}, . . a_{B n}\right)$ şeklindedir.

$\mathrm{a}_{\mathrm{Bj}}$ : kriter j üzerinden, en iyi kriterin B tercihinin gösterilmesidir.

Tablo 1. Kriterler için Karşılaştırma Ölçeği

\begin{tabular}{lllllll}
\hline Ölçek & $\mathbf{1}$ & $\mathbf{3}$ & $\mathbf{5}$ & $\mathbf{7}$ & $\mathbf{9}$ & $\mathbf{2 , 4 , 6 , 8}$ \\
\hline $\begin{array}{l}\text { Değer } \\
\text { Tanımı }\end{array}$ & Eşit & Orta & Güçlü & Çok & Mutlak & Ara \\
& & & Güçlü & Üstün & Değerler \\
\hline
\end{tabular}

Adım 4. Bütün kriterlerin belirlenen en kötü kritere göre tercihi 1 ile 9 arasındaki sayı ile ifade edilir (Tablo 1). En kötü kritere göre oluşan vektör $A_{W}=\left(a_{1 W}, a_{2 W}, . ., a_{n W}\right)^{T}$ şeklindedir.

$\mathrm{a}_{\mathrm{jw}}=$ kriter j'nin, en kötü kriter W üzerindeki tercihidir. 
Adım 5. Optimal ağırlıklar $\left(\mathrm{w}_{1}^{*}, \mathrm{w}_{2}^{*}, \ldots, \mathrm{w}_{\mathrm{n}}^{*}\right)$ elde edilir.

Kriterler için optimal ağırlık $w_{B}=w_{j}$ ve $w_{j}=w_{W}$ olduğu yerde, $\mathrm{w}_{\mathrm{B}} / \mathrm{w}_{\mathrm{j}} \mathrm{ve} \mathrm{w}_{\mathrm{j}} / \mathrm{w}_{\mathrm{w}}$ olarak ifade edilmektedir.

Tüm j için koşulları sağlayacak şekilde bulunan çözüm;

$$
\min \max _{\mathrm{j}}\left(\left|\frac{\mathrm{w}_{\mathrm{B}}}{\mathrm{w}_{\mathrm{j}}}-\mathrm{a}_{B J}\right|\left|\frac{\mathrm{w}_{\mathrm{j}}}{\mathrm{w}_{\mathrm{w}}}-\mathrm{a}_{j w}\right|\right)(1)
$$

$\left(\frac{w_{B}}{w_{j}}\right.$ : en iyi kriterin ağırlığının j.kriterin ağırlığına oranıdır.)

$\left(\frac{w_{j}}{w_{w}}: j\right.$. kriterin ağırlığının en kötü kriterin ağırlığgna oranıdır.)

Modelde amaçlanan tutarlılık oranının minimum seviyede kalmasıdır. $\mathrm{Bu}$ sebeple modelin amaç fonksiyonu tutarlılık oranının en küçüklendiği şekilde ifade edilmektedir. Eşitlik 1'de ağırlıkların negatif olmaması gerektiğinden revize edilen doğrusal model aşağıda şekilde oluşturulmuştur:

$\operatorname{Min} \xi(2)$

$$
\left|\mathrm{W}_{\mathrm{B}}-\mathrm{W}_{\mathrm{j}} \mathrm{a}_{\mathrm{Bj}}\right| \leq \xi
$$$$
\left|\mathrm{W}_{\mathrm{j}}-\mathrm{W}_{\mathrm{W}} \mathrm{a}_{\mathrm{jw}}\right| \leq \xi
$$$$
\sum \mathrm{W}_{\mathrm{j}}=1 ; \mathrm{W}_{\mathrm{j}} \geq 0
$$

$\left(\left|\mathrm{W}_{\mathrm{B}}-\mathrm{W}_{\mathrm{j}} \mathrm{a}_{\mathrm{Bj}}\right| \leq \xi\right.$ denklemi; en iyi kriterin ağırlığının, j.kriterin ağırlığı ile kriter j üzerinden, en iyi kriterin B tercihinin çarpımı arasındaki farkın tutarlılık oranından küçük veya eşit olduğunu göstermektedir.)

$\left(\left|\mathrm{W}_{\mathrm{j}}-\mathrm{W}_{\mathrm{W}} \mathrm{a}_{\mathrm{jw}}\right| \leq \xi\right.$ denklemi; j. kriterin ağırlığının, en kötü kriterin ağırlığı ile kriter j'nin, en kötü kriter W üzerindeki tercihinin çarpımı arasındaki farkın tutarlılık oranından küçük veya eşit olduğunu göstermektedir.)

$\left(\sum \mathrm{W}_{\mathrm{j}}=1\right.$ ve $\mathrm{W}_{\mathrm{j}} \geq 0$ : tüm kriterlerin ağırlık değerlerinin 0'dan büyük ve herbir ağırlığın toplamının 1'e eşit olduğunun ifadeleridir.)

$\mathrm{Bu}$ model çözümünün ardından, kriterlerin ağırlıkları ve $\xi$ (tutarlılık oranı) değerine ulaşılmaktadır.

Adım 6. Çalışmanın tutarlılığına karar verilir. Bu adımda Razei (2015)'nin çalışmasında yer verdiği tutarlılık indeks tablosundan yararlanılır.

Tablo 2. Tutarlılık Indeks (CI) Tablosu

\begin{tabular}{llllllllll}
\hline aвw & 1 & 2 & 3 & 4 & 5 & 6 & 7 & 8 & 9 \\
\hline CI & 0.00 & 0.44 & 1.00 & 1.63 & 2.30 & 3.00 & 3.73 & 4.47 & 5.23
\end{tabular}

Çalışmanın Tutarlık Oranı şu şekilde hesaplanmaktadır:

$$
(\mathrm{CR})=\frac{\xi}{\mathrm{CI}}
$$

$\mathrm{Bu}$ değerin 1'in altında olması durumunda, verilerin yeterli tutarlılığa sahip olduğu kabul edilmektedir (Rençber \& Avc1, 2018).

Buraya kadar ifade edildiği üzere BWM ile çözümlenecek problemler için önerilen denklemler, basit doğrusal programlama (Lineer Programming (LP)) modelini ifade etmektedir. Doğrusal Programlama problemleri Excel üzerinde hücrelere kriterlerin yerleştirilmesi, karar vericiler tarafindan yapılan tercih düzeylerinin girilmesi (Tablo 1'e göre) ve ilgili denklemlerin (Eşitlik 2) çözücü yardımıyla yazılması doğrultusunda kolaylıkla e-ISSN: 2148-2683 algoritma çözümü elde edilmektedir. Eşitlik (2)'de yazan parametrelerin ve denklemlerin her biri bu algoritmada yer almaktadir.

\section{Uygulama}

Çalışmanın uygulama kısmında yer alan tüm karar vericiler bulundukları işletmenin sürdürülebilirlik departmanında 5 yıl veya daha fazla süredir tam zamanlı çalışan mühendislerden oluşmaktadır. Karar vericiler endüstri veya çevre mühendisliği mesleklerine sahip olan kişilerdir. Çalışmada cam, çelik ve plastik olmak üzere üç farklı endüstriden altışar kişi ile toplamda 18 uzmanla görüşülmüştür.

Çalışma toplam 7 kriterden oluşmaktadır (Şekil 2). Kriterlerden ikisi ekonomik, ikisi sosyal ve üçü çevresel sürdürülebilirlik boyutlarından oluşmaktadır. Çalışmada yer alan kriterler ilk olarak Bölüm 2.1'de yer alan mevcut literatürden çalışmayla bağlantılı olacak şekilde kurgulanmıştır. Ardından belirlenen kriterler için sekiz farklı uzmanla görüşülmüş ve bu kriterler uzmanlar tarafindan uygun bulunduktan sonra tüm karar vericilere BWM uygulaması yapılmıştır.

\section{Şekil 2. Çalışma Kriterleri}

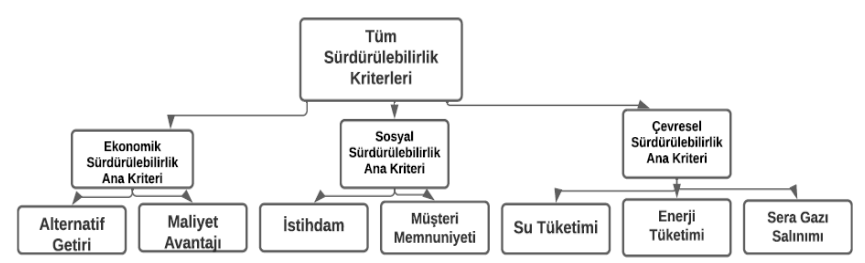

Ekonomik Sürdürülebilirlik Boyutları;

C1 (Alternatif Getiri): Firmanın atık olarak ayırdığı ürünleri dış kaynak kullanımı ile geri dönüştürme sonucunda tekrar üretim faaliyetlerinde kullanmasının sağladığı ekonomik kazancı göstermektedir. Firma üretim süreçlerinde kullanacağı bu malzemeyi dışarıdan satın almak yerine tekrar kullanılacak hale dönüştürmektedir. Bu da alternatif bir getiri sağlamaktadır.

C2 (Elde edilen maliyet avantaj1): Firmanın üretim süreçlerinde kullanacağı bir malzemeyi dışarıdan satın almak için ödeyeceği maliyet ile aynı malzemeyi atık olarak ayırdığ ürünlerden tekrar geri dönüşümle kazanması için katlanacağ 1 maliyet arası farkı yansıtmaktadır.

Sosyal Sürdürülebilirlik Boyutları;

C3 (İstihdam): Yeni bir iş kolunun dahil edilmesiyle firmanın yeni çalışan ihtiyacı içine girebilme durumunu yansitmaktadir.

C4 (Müşteri Memnuniyeti): Günümüzde tüketiciler sahip olduğu ürünü üreten üretici firmanın toplumsal konumuna ve sosyal durumuna da dikkat etmektedir. $\mathrm{Bu}$ sebeple firmaların toplum bilinciyle faaliyet göstermesi müşteriler açısından önemli olmaktadir.

\section{Çevresel Sürdürülebilirlik Boyutları;}

C5 (Su Tüketimi): Firmanın geri dönüşüm faaliyetini gerçekleştirmesiyle tasarruf edilen su miktarını yansıtmaktadır.

C6 (Enerji Tüketimi): Firmanın geri dönüşüm faaliyetini gerçekleştirmesiyle tasarruf edilen enerji miktarını yansıtmaktadır. Enerji hem kullanılan yakıt hem de elektrik tüketiminin birleşimden oluşmaktadır. 
C7 (Sera Gazı Salınımı): Firmanın geri dönüşüm faaliyetini gerçekleştirmesiyle çevreye yaydığı sera gazındaki farkı yansitmaktadir.

\subsection{Plastik Sektöründe Uygulama}

Plastik sektöründe faaliyet gösteren işletmelerin sürdürülebilirlik departmanında çalışan altı mühendis ile yapılan görüşmeler sonucunda en iyi kriter ve en kötü kriter belirlenerek diğer kriterlere ağırlıklar verilmiştir. Her karar vericiden ayrı olarak toplanan bilgiler aşağıdaki tablolarda birleştirilmiştir.

\section{Tablo 3. En İyi Kritere Göre Karar Vericilerin Değerlendirme} Tablosu (Plastik Endüstrisi)

\begin{tabular}{lllllllll}
\hline $\begin{array}{l}\text { Karar } \\
\text { Vericiler }\end{array}$ & $\begin{array}{c}\text { En } \\
\text { Iyi }\end{array}$ & $\mathbf{C 1}$ & $\mathbf{C 2}$ & $\mathbf{C 3}$ & $\mathbf{C 4}$ & $\mathbf{C 5}$ & $\mathbf{C 6}$ & $\mathbf{C 7}$ \\
\hline $\mathbf{K V}_{\mathbf{1}}$ & $\mathrm{C} 1$ & 1 & 2 & 9 & 3 & 7 & 5 & 7 \\
\hline $\mathbf{K V}_{\mathbf{2}}$ & $\mathrm{C} 2$ & 3 & 1 & 9 & 5 & 7 & 5 & 7 \\
\hline $\mathbf{K V}_{\mathbf{3}}$ & $\mathrm{C} 2$ & 2 & 1 & 9 & 5 & 5 & 5 & 7 \\
\hline $\mathbf{K V}_{\mathbf{4}}$ & $\mathrm{C} 1$ & 1 & 3 & 7 & 3 & 9 & 5 & 5 \\
\hline $\mathbf{K V}_{\mathbf{5}}$ & C2- & 1 & 1 & 7 & 3 & 5 & 5 & 9 \\
\hline $\mathbf{K V}_{\mathbf{6}}$ & $\mathrm{C} 1$ & 1 & 3 & 7 & 4 & 5 & 5 & 9 \\
\hline
\end{tabular}

Tablo 3'de dış kaynak kullanımı olarak geri dönüşüm faaliyetlerini üretim süreçlerine dahil etmeyi planlayan plastik sektöründeki firma çalışanlarının belirledikleri en iyi kriterler ve diğer kriterlere verdikleri ağırlıklar gösterilmektedir. Karar vericiler bu aşamada Tablo 1'den yararlanarak değerlendirmelerini yapmıştır. Karar vericilerden biri tarafından birden fazla kriter en iyi kriter olarak değerlendirilmiştir. Böyle bir durumda problem çözümü için yöntemde herhangi bir sınırlandırma bulunmamaktadır. Doğrusal programlama ile modellenen problemde, analiz için öncelik ilk tanımlanmış kritere verilmektedir (Yukarıdaki tablo için C1 kriteri). Ancak aksi de olsa model çözümünde ulaşılan değerler değişmemektedir. Tabloya göre karar vericiler için en iyi kriter C1 (alternatif getiri) veya C2 (maliyet avantaj1) 'dir. Bu adımdan sonra her karar verici için en kötü kriter (en arkıl) belirlenmektedir.

Tablo 4. En Kötü Kritere Göre Karar Vericilerin Değerlendirme Tablosu(Plastik Endüstrisi)

\begin{tabular}{lllllll} 
& $\mathbf{K V}_{\mathbf{1}}$ & $\mathbf{K V}_{\mathbf{2}}$ & $\mathbf{K V}_{\mathbf{3}}$ & $\mathbf{K V}_{\mathbf{4}}$ & $\mathbf{K V}_{\mathbf{5}}$ & $\mathbf{K V}_{\mathbf{6}}$ \\
\hline Kriterler & En & En & En & En & En & En \\
& kötü:C3 & kötü:C3 & kötü:C3 & kötü:C3 & kötü:C7 & kötü:C3 \\
C1 & 9 & 4 & 5 & 7 & 9 & 9 \\
\hline C2 & 5 & 9 & 9 & 2 & 9 & 4 \\
\hline C3 & 1 & 1 & 1 & 1 & 3 & 1 \\
\hline C4 & 4 & 2 & 2 & 3 & 4 & 3 \\
\hline C5 & 2 & 2 & 2 & 2 & 2 & 2 \\
\hline C6 & 3 & 3 & 2 & 2 & 2 & 2 \\
C7 & 2 & 2 & 1 & 2 & 1 & 1 \\
\hline
\end{tabular}

Tablo 4'de plastik sektöründeki her karar verici tarafindan belirlenen en kötü kriter (arkil) ve diğer kriterlere 1-9 arasında verilen ağırlıklar gösterilmektedir. Karar vericiler bu aşamada Tablo 1'den yararlanmıştır. En kötü ağırlık, bu çalışma için geri dönüşüm kararı vermelerinde etkili olan kriterler için en son değerlendirilecek kriter olduğunu söylemektedir. Tabloya göre karar vericiler tarafından en kötü kriterin C3 (istihdam) veya C7 (sera gazı salınım)'den herhangi biri olduğu görülmektedir.

Tablo 5. Kriterlerin A ğırlıkları ve Tutarlılık Oranları (Plastik Endüstrisi)

\begin{tabular}{lllllllll}
\hline & $\mathbf{C 1}$ & $\mathbf{C 2}$ & $\mathbf{C 3}$ & $\mathbf{C 4}$ & $\mathbf{C 5}$ & $\mathbf{C 6}$ & $\mathbf{C 7}$ & $\mathbf{C R}$ \\
\hline $\mathbf{K V}_{\mathbf{1}}$ & 0,394 & 0,214 & 0,040 & 0,142 & 0,061 & 0,085 & 0,061 & 0,0342 \\
\hline $\mathbf{K V}_{\mathbf{2}}$ & 0,164 & 0,452 & 0,045 & 0,098 & 0,070 & 0,098 & 0,070 & 0,0393 \\
\hline $\mathbf{K V}_{\mathbf{3}}$ & 0,216 & 0,420 & 0,045 & 0,086 & 0,086 & 0,086 & 0,058 & 0,0124 \\
\hline $\mathbf{K V}_{\mathbf{4}}$ & 0,408 & 0,153 & 0,051 & 0,153 & 0,051 & 0,091 & 0,091 & 0,0510 \\
\hline $\mathbf{K V}_{\mathbf{5}}$ & 0,324 & 0,324 & 0,052 & 0,121 & 0,073 & 0,073 & 0,031 & 0,0418 \\
\hline $\mathbf{K V}_{\mathbf{6}}$ & 0,424 & 0,159 & 0,053 & 0,119 & 0,095 & 0,095 & 0,053 & 0,0530 \\
\hline $\mathbf{W}_{\mathbf{j}}$ & $\mathbf{0 , 3 2 1}$ & $\mathbf{0 , 2 8 7}$ & $\mathbf{0 , 0 4 7}$ & $\mathbf{0 , 1 2 0}$ & $\mathbf{0 , 0 6 2}$ & $\mathbf{0 , 0 8 8}$ & $\mathbf{0 , 0 5 7}$ & $\mathbf{0 , 3 8 6 3}$ \\
\hline
\end{tabular}

Tablo 5, her karar vericiye ait kriterlerin ağırlıklarının ve tutarlılık oranlarının gösterildiği tablodur. Tablodaki değerlere Excel Programının çözücüsü ile ulaşılmıştır. Tutarlılık oranı (CR)'nın genel ortalama değeri 0,3863 olarak hesaplanmıştır.

\subsection{Cam Sektöründe Uygulama}

Cam sektöründe faaliyet gösteren işletmelerin sürdürülebilirlik departmanında çalışan 6 mühendis ile yapılan görüşmeler sonucunda en iyi kriterin ve en kötü kriterin belirlenerek diğer kriterlere de verdikleri değerler aşağıda tablolarda gösterilmiştir.

Tablo 6. En İyi Kritere Göre Karar Vericilerin Değerlendirme Tablosu (Cam Endüstrisi)

\begin{tabular}{|c|c|c|c|c|c|c|c|c|}
\hline $\begin{array}{l}\text { Karar } \\
\text { Vericiler }\end{array}$ & $\begin{array}{l}\text { En } \\
\text { İyi }\end{array}$ & C1 & C2 & C3 & C4 & C5 & C6 & C7 \\
\hline $\mathbf{K V}_{7}$ & $\mathrm{C} 1$ & 1 & 2 & 9 & 3 & 5 & 4 & 7 \\
\hline $\mathrm{KV}_{8}$ & $\begin{array}{l}\text { C1- } \\
\text { C2 }\end{array}$ & 1 & 1 & 7 & 4 & 9 & 5 & 5 \\
\hline$K_{V_{9}}$ & $\mathrm{C} 2$ & 3 & 1 & 9 & 5 & 7 & 5 & 6 \\
\hline$K^{K V_{10}}$ & $\mathrm{C} 1$ & 1 & 2 & 9 & 3 & 9 & 5 & 7 \\
\hline$K_{11}$ & $\begin{array}{l}\text { C1- } \\
\text { C2 }\end{array}$ & 1 & 1 & 7 & 4 & 9 & 4 & 5 \\
\hline$K_{12}$ & C1 & 1 & 2 & 7 & 9 & 9 & 3 & 7 \\
\hline
\end{tabular}

Tablo 6'da dıș kaynak kullanımı olarak geri dönüşüm faaliyetlerini üretim süreçlerine dahil etmeyi planlayan cam endüstrisindeki firma çalışanlarının, belirledikleri en iyi kriterler ve diğer kriterlere verdikleri ağırlıklar gösterilmektedir. Tablo 6'ya bakıldığında karar vericiler için en iyi kriterin C1 (alternatif getiri) veya C2 (maliyet avantajı) olarak ifade edildiği görülmektedir. Bir sonraki adımda her karar verici için en kötü kriter belirlenmektedir.

Tablo 7. En Kötü Kritere Göre Karar Vericilerin Değerlendirme Tablosu (Cam Endüstrisi)

\begin{tabular}{lllllll}
\hline & $\mathbf{K V}_{\mathbf{7}}$ & $\mathbf{K V} \mathbf{8}$ & $\mathbf{K V} \mathbf{9}$ & $\mathbf{K V}_{\mathbf{1 0}}$ & $\mathbf{K V}_{\mathbf{1 1}}$ & $\mathbf{K V}_{\mathbf{1 2}}$ \\
\hline Kriterler & $\begin{array}{l}\text { En } \\
\text { kötü:C3 }\end{array}$ & $\begin{array}{l}\text { En } \\
\text { kötü:C5 }\end{array}$ & $\begin{array}{l}\text { En } \\
\text { kötü:C3 }\end{array}$ & $\begin{array}{l}\text { En } \\
\text { kötü:C3- } \\
\text { C5 }\end{array}$ & $\begin{array}{l}\text { En } \\
\text { kötü:C5 }\end{array}$ & $\begin{array}{l}\text { En } \\
\text { kötü:C5 }\end{array}$ \\
\hline C1 & 9 & 9 & 3 & 9 & 9 & 9 \\
\hline C2 & 7 & 9 & 9 & 5 & 9 & 6 \\
\hline C3 & 1 & 1 & 1 & 1 & 2 & 1 \\
\hline C4 & 4 & 3 & 2 & 4 & 3 & 1 \\
\hline C5 & 2 & 1 & 1 & 1 & 1 & 1 \\
\hline C6 & 2 & 2 & 2 & 2 & 3 & 3 \\
\hline C7 & 2 & 2 & 1 & 2 & 2 & 2 \\
\hline
\end{tabular}

Tablo 7'de cam endüstrisindeki karar vericiler tarafindan belirlenen en kötü kritere göre diğer kriterlerin değerlendirilmesi yapılmıştır. Tablo 7 karar vericiler tarafından en kötü kriterin C3 (istihdam) veya C5 (su tüketimi)'den herhangi biri olduğunu göstermektedir. 
Tablo 8. Kriterlerin Ağırlıkları ve Tutarlılık Oranları (Cam Endüstrisi)

\begin{tabular}{lllllllll} 
& $\mathbf{C 1}$ & $\mathbf{C 2}$ & $\mathbf{C 3}$ & $\mathbf{C 4}$ & $\mathbf{C 5}$ & $\mathbf{C 6}$ & $\mathbf{C 7}$ & $\mathbf{C R}$ \\
\hline KV $_{\mathbf{7}}$ & 0,370 & 0,207 & 0,036 & 0,138 & 0,083 & 0,103 & 0,059 & 0,045 \\
\hline KV $_{\mathbf{8}}$ & 0,321 & 0,362 & 0,040 & 0,090 & 0,040 & 0,072 & 0,072 & 0,040 \\
\hline $\mathbf{K V}_{\mathbf{9}}$ & 0,158 & 0,456 & 0,052 & 0,095 & 0,068 & 0,095 & 0,072 & 0,019 \\
\hline KV $_{\mathbf{1 0}}$ & 0,404 & 0,214 & 0,042 & 0,143 & 0,047 & 0,085 & 0,061 & 0,025 \\
\hline KV $_{\mathbf{1 1}}$ & 0,333 & 0,333 & 0,050 & 0,088 & 0,034 & 0,088 & 0,070 & 0,019 \\
KV $_{\mathbf{1 2}}$ & 0,394 & 0,226 & 0,047 & 0,064 & 0,050 & 0,151 & 0,064 & 0,059 \\
\hline $\mathbf{W}_{\mathbf{j}}$ & $\mathbf{0 , 3 3 0}$ & $\mathbf{0 , 3 0 0}$ & $\mathbf{0 , 0 6 0}$ & $\mathbf{0 , 1 0 3}$ & $\mathbf{0 , 0 5 4}$ & $\mathbf{0 , 0 9 9}$ & $\mathbf{0 , 0 6 6}$ & $\mathbf{0 , 0 3 4}$ \\
\hline
\end{tabular}

Tablo 8' göre cam endüstrisinde yapılan uygulamaya ait tutarlılık oranının (CR) genel ortalama değeri 0,0349 olarak hesaplanmıştır.

\section{3. Çelik Sektöründe Uygulama}

Çelik sektöründe faaliyet gösteren işletmelerin sürdürülebilirlik departmanında çalı̧an 6 mühendis ile yapılan görüşmeler sonucunda en iyi kriterin ve en kötü kriterin belirlenerek diğer kriterlere de verdikleri değerler aşağıdaki tablolarda gösterilmiş̧ir.

Tablo 9. En İi Kritere Göre Karar Vericilerin Değerlendirme Tablosu (Çelik Endüstrisi)

\begin{tabular}{lllllllll}
$\begin{array}{l}\text { Karar } \\
\text { Vericiler }\end{array}$ & $\begin{array}{l}\text { En } \\
\text { İi }\end{array}$ & C1 & C2 & C3 & C4 & C5 & C6 & C7 \\
\hline KV13 & C1 & 1 & 2 & 5 & 5 & 7 & 6 & 9 \\
\hline KV 14 & C1 & 1 & 3 & 7 & 3 & 5 & 4 & 9 \\
\hline $\mathbf{K V}_{15}$ & C1- & 1 & 1 & 9 & 5 & 5 & 4 & 7 \\
\hline $\mathbf{K V}_{16}$ & C2 & 2 & 1 & 9 & 7 & 7 & 5 & 5 \\
\hline $\mathbf{K V}_{17}$ & C1 & 1 & 3 & 7 & 5 & 9 & 5 & 5 \\
\hline $\mathbf{K V}_{18}$ & C2 & 2 & 1 & 7 & 5 & 7 & 5 & 9 \\
\hline
\end{tabular}

Tablo 9'a bakıldığında karar vericiler için en iyi kriterin C1 (alternatif getiri) veya $\mathrm{C} 2$ (maliyet avantaj1) olduğu görülmektedir. Bir sonraki adımda her karar verici için en kötü kriter belirlenmektedir.

Tablo 10. En Kötü Kritere Göre Karar Vericilerin Değerlendirme Tablosu (Çelik Endüstrisi)

$\begin{array}{lllllll} & \text { KV }_{13} & \mathbf{K V}_{14} & \mathbf{K V}_{15} & \mathbf{K V}_{16} & \mathbf{K V}_{17} & \text { KV }_{18} \\ \text { Kriterler } & \text { En } & \text { En } & \text { En } & \text { En } & \text { En } & \text { En } \\ & \text { kötü:C7 } & \text { kötü:C5- } & \text { kötü:C3 } & \text { kötü:C3 } & \text { kötü:C5 } & \text { kötü:C7 } \\ & & \text { C7 } & & & & \end{array}$

\begin{tabular}{lllllll}
\hline C1 & 9 & 9 & 9 & 7 & 9 & 7 \\
\hline C2 & 5 & 6 & 9 & 9 & 7 & 9 \\
\hline C3 & 2 & 2 & 1 & 1 & 2 & 2 \\
\hline C4 & 3 & 2 & 3 & 2 & 3 & 3 \\
\hline C5 & 1 & 1 & 2 & 2 & 1 & 2 \\
\hline C6 & 1 & 2 & 3 & 3 & 3 & 3 \\
\hline C7 & 1 & 1 & 2 & 3 & 3 & 1 \\
\hline
\end{tabular}

Tablo 10'da çelik endüstrisindeki karar vericiler tarafından belirlenen en kötü kritere göre diğer kriterlerin değerlendirilmesi yapılmış ve karar vericiler tarafından en kötü kriterin C3 (istihdam), C5 (su tüketim azalımı) veya C7 (sera gazı salınım azalımı)'den herhangi biri olduğu görülmüştür.

Tablo 11. Kriterlerin Ağırlikları ve Tutarlılık Oranları (Çelik Endüstrisi)

\begin{tabular}{lllllllll}
\hline & C1 & C2 & C3 & C4 & C5 & C6 & C7 & CR \\
\hline KV $_{13}$ & 0,405 & 0,231 & 0,092 & 0,092 & 0,049 & 0,077 & 0,051 & 0,056 \\
\hline $\mathbf{K V}_{\mathbf{1 4}}$ & 0,370 & 0,165 & 0,070 & 0,165 & 0,048 & 0,124 & 0,055 & 0,126 \\
\hline $\mathbf{K V}_{\mathbf{1 5}}$ & 0,337 & 0,337 & 0,034 & 0,073 & 0,073 & 0,091 & 0,052 & 0,029 \\
\hline $\mathbf{K V}_{\mathbf{1 6}}$ & 0,231 & 0,411 & 0,040 & 0,066 & 0,066 & 0,092 & 0,092 & 0,050 \\
\hline KV $\mathbf{1 7}$ & 0,418 & 0,168 & 0,072 & 0,101 & 0,036 & 0,101 & 0,101 & 0,088 \\
\hline KV $\mathbf{1 8}$ & 0,231 & 0,411 & 0,066 & 0,092 & 0,066 & 0,092 & 0,040 & 0,050 \\
\hline $\mathbf{W}_{\mathbf{J}}$ & $\mathbf{0 , 3 3 2}$ & $\mathbf{0 , 2 8 7}$ & $\mathbf{0 , 0 6 2}$ & $\mathbf{0 , 0 9 8}$ & $\mathbf{0 , 0 5 6}$ & $\mathbf{0 , 0 9 6}$ & $\mathbf{0 , 0 6 5}$ & $\mathbf{0 , 0 6 6}$ \\
\hline
\end{tabular}

Tablo 11'e göre çelik endüstrisinde yapılan uygulamaya ait tutarlılık oranının (CR) genel ortalama değeri 0,0668 olarak hesaplanmıştır.

\section{Sonuç ve Değerlendirme}

Günümüzde kaynakların bilinçsizce kullanımı, atık miktarlarındaki artış ve ekosistemde yaratılan kirlilik gibi çevresel endişeler, müşteri ve çalışanlar tarafindan istenen sosyal haklar, rekabet ve finansal gücü sağlayan ekonomik baskılar endüstriyel sistemleri sürdürülebilir olmaya yaklaştırmaktadır. İşletmelerin harekete geçtiği sürdürülebilir çabalardan biri atık yönetimlerini sağlayacakları geri dönüşüm faaliyetleridir. Firmaların kendi faaliyet alanlarının dışına çıkmadan dış kaynak kullanımı ile geri dönüşüm faaliyetlerine olan isteği artmaya başlamış ve bu kararları vermeden çeşitli senaryoları değerlendirmek istemektedir. Bu çalışmada da geri dönüşüm faaliyetlerini uygulamak isteyen üç farklı endüstrinin kararlarını şekillendirmede belirleyici olan kriterler uzmanlarca değerlendirilmiş ve önceliklendirilmiştir.

Üç endüstride de ulaşılan sonuçlarda tutarlılık oranının 0 'a nispeten yakın olduğu görülmektedir (Tablo 12).

\section{Tablo 12. Tutarlılık Oran Tablosu}

\begin{tabular}{c|c|c} 
Plastik Endüstrisi & Cam Endüstrisi & Çelik Endüstrisi \\
\hline 0,3863 & 0,0349 & 0,0668 \\
\hline
\end{tabular}

Bu değerin 1'in altında kalıyor olması ve 0'a yaklaşması Razei (2015) tarafindan karar vericilerin yaptıkları değerlendirmelerde başarılı ve kabul edilebilir bir tutarlılığın göstergesi olarak görülmüştür.

İlk olarak plastik sektöründe ulaşılan sonuçlara tutarlılık oranının 1'den küçük olması sebebiyle güvenileceği ifade edilmelidir. Çalışma sonuçlarına göre geri dönüşüm kararını etkileyen en iyi kriter 0,3218 ağırlık oranıyla alternatif getiri, ikinci en iyi kriterin 0,2872 ağırlık oranıyla elde edilen maliyet avantajı olduğu görülmüştür. İki kriterin de finansal bir boyut olması sebebiyle, plastik endüstrisindeki işletmelerin geri dönüşüm kararı vermelerinde en büyük etkinin ekonomik sürdürülebilirlik kriterleri tarafından sağlandığı söylenebilir. Çünkü analiz sonucunda iki ekonomik göstergenin etkisinin tüm göstergeler içinde yaklaşık \%60'a (toplam 0,609 ağırlık oranı) ulaştığı görülmektedir. Üçüncü en iyi kriter ise 0,1203 ağırlık oranıyla sosyal sürdürülebilirlik kriterlerinden müşteri memnuniyetidir. Verilecek kararda en az belirleyici (kötü) kriter ise diğer sosyal sürdürülebilirlik boyutu olan istihdam olarak belirlenmiştir. Yani yeni bir iş kolunun dahil edilmesiyle tesis içerisinde bir iş olanağının yaratılması, karar vericiler tarafından diğer kriterlere nazaran önemli görülen bir durum değildir. 
Çevresel sürdürülebilirlik kriterleri ise ekonomik sürdürülebilirlik hedeflerine göre daha az önemli görülmüştür.

Cam sektöründe gerçekleştirilen uygulama sonuçlarına göre 0,0349 ağırlık oranıyla en iyi tutarlılık oranına ulaşılmıştır. Bu değer ulaşılan sonuçlara güvenilebileceğini göstermektedir. Tablo sonuçları değerlendirildiğinde geri dönüşüm kararını etkileyen en iyi kriterin 0,3305 ağırlık oranıyla alternatif getiri, ikinci en iyi kriterin 0,300 ağırlık oranıyla elde edilen maliyet avantajı olduğu görülmüştür. Geri dönüşüm kararını etkileyen finansal göstergeler tüm göstergelerin içinde 0,6305 ağırlık oranına sahip olması sebebiyle önemlidir. Üçüncü en iyi kriter ise 0,103 ağırlık oranıyla müşteri memnuniyetidir. Diğer kriterler önem sırasıyla enerji tüketimi, sera gazı ve istihdamdır. Son olarak 0,0540 ağırlık oranıyla su tüketim kriteri, cam sektöründe geri dönüşüm kararı verilmesinde en az etkili olan kriter olarak belirlenmiştir. Çevresel sürdürülebilirliğin bir boyutu olan su tüketimi, cam sektöründeki uzmanların kararını diğerlerine nazaran en son sırada etkilemektedir.

Son uygulama alanı olan çelik sektöründe analiz sonucunda ulaşılan 0,0668 tutarlılık oranı ile karar vericiler tarafindan yapılan değerlendirilmelere güvenilebileceği gözükmektedir. Çelik sektöründe verilmesi planlanan geri dönüşüm kararında etkili olan en iyi kriter 0,3322 ağırlık oranıyla alternatif kazanç ve diğer en iyi kriter 0,2877 ağırlık oranıyla maliyet avantajı olarak belirlenmiştir. Diğer kriterlerin ağırlık puanlarına bakıldığında önem sırasına göre müşteri memnuniyeti, enerji tüketimi, sera gazı salınımı istihdam kararda etkili olmuştur. En düşük ağırlığa sahip su tüketimi ise, çelik sektöründe dış kaynak kullanımında geri dönüşüm faaliyet kararı açısından en geride kalan kriterdir.

Tüm sektörlere genel açıdan bakıldığında üç sektör için de ekonomik sürdürülebilirlik kriterleri, geri dönüşüm kararında en belirleyici olan boyutlar olarak ortaya çıkmıştır. Aynı zamanda alternatif kazanç kriteri, tüm sektörlerde verilecek kararın en iyi kriteri olarak tespit edilmiştir. Plastik, cam ve çelik sektörü uygulama sonuçlarında en yüksek ağırlığa sahip üçüncü kriter de ortak olarak müşteri memnuniyetidir. Karar vericiler tarafindan bu kritere yüksek önem verilmesinde, uzun dönemde müşteri memnuniyetinin firmanın olası sürdürülebilirlik sonuçlarına büyük katkı vereceği beklentisi olabilir. Özetle, firmaların geri dönüşüm kararı vermelerinde etkili olan en önemli ilk üç kriteri, sektörel olarak değişmemektedir. Analiz sonucunda en düşük ağırlığa sahip (en kötü) kriter ise plastik sektöründe istihdam olurken, çelik ve cam endüstrisinde su tüketimi olmuştur.

Çalışmada eş zamanlı incelenen boyutların, sektörel karşılaştırmaların ve uzman görüşleri sonucunda ulaşılan sonuçların, alanın ilk çalışması olması sebebiyle hem literatüre hem de sektördeki uygulayıcılara katkı sağlaması beklenmektedir.

Bundan sonraki araştırmalar için çalışmada incelenen plastik, cam ve çelik endüstrilerine ilave olarak eklenecek faklı ürün grupları da çalışmayı genişletecektir. Ayrıca çalışmanın sadece tehlikesiz endüstriyel atıklar için yapılmış olması sebebiyle, benzer sektörlerdeki tehlikeli atıklar için de yeni yapılacak çalışmaların literatüre destek sağlayacağ beklenmektedir. Tehlikeli atıklar için yapılması muhtemel çalışmalarda farklı sürdürülebilirlik boyutlarının çalışmaya yeni kriterler olarak eklenmesi de bu alandaki çalışmalara farklı bakış açılarını sunabilir. Bu sayede hem tehlikeli hem de tehlikesiz atıklar için çıkan sonuçlar karşılaştırılarak benzerlikler veya farklılıklar tartışılabilir.

e-ISSN: 2148-2683

\section{Kaynakça}

Abdelazis, F.B., Alaya, H., \& Dey, P.K. (2020). A multiobjective particle swarm optimization algorithm for business sustainability analysis of small and medium sized enterprises, Annals of Opr. Res, (293), 557-86.

Alba Ingenieros. (2012). S. La Energía de los Residuos. Erişim Tarihi:

31.07.2021

https://www.fenercom.com/publicacion/la-energia-delosresiduos/.

Ahi, P., \& Searcy, C. (2015). An analysis of metrics used to measure performance in green and sustainable supply chains. Journal of Cleaner Production, 86 (1), 360-377.

Ameer, R. \& Othman, R. (2012). Sustainability practices and corporate financial performance: A study based on the top global corporations. Journal of Business Ethics, 108 (1), 6179.

Chaudhary, K., \& Vrat, P. (2020). Circular economy model of gold recovery from cell phones using system dynamics approach: a case study of India. Environment, Development and Sustainability, 22, 173-200.

Dubey, R., Gunasekaran, A., Childe, S. J., Papadopoulos T., Luo, Z., \& Roubaud, D. (2020). Upstream supply chain visibility and complexity effect on focal company's sustainable performance: Indian manufacturers' perspective. Annals of Opr. Res. (290), 343-67.

Elliott, S. R. (2005). Sustainability: an economic perspective. Resources. Conservation and Recycling, 44, 263-277.

Eltayeb, T. K. \& Zailani, S. (2010). Investigation on the drivers of green purchasing towards environmental sustainability in the Malaysian manufacturing sector. Int. J. Procurement Management, 3(3), 316.

EPA. (2018). Durable Goods: Product-Specific Data. Erişim Tarihi: 1.08.2021, https://www.worldsteel.org/aboutsteel/steel-facts.html.

Erol, İ., \& Özmen, A. (2018). Çevresel düzeyde sürdürülebilirlik performansının ölçülmesi: Parekende sektöründe bir uygulama. İktisat İşletme ve Finans, 23(266), 70-94.

Gatimbu, K., Ogada, M., Budambula, N., \& Kariuk, S. (2018). Environmental sustainability and financial performance of the small-scale tea processors in Kenya. Business Strategy \& the Environment, John Wiley \& Sons, 27(8), 1765-1771.

Glavas, A., \& Mish, J. (2015). Resources and capabilities of triple bottom line firms: going over old or breaking new ground?. Journal of Business Ethics, 127(3), 623-642.

Goodland, R. (1995). The Concept of environmental sustainability. Annual Review of Ecology and Systematics, , $1-24$.

Govindan, K., Jha, P. C., Agarwal, V., \& Darbari, J. D. (2019). Environmental management partner selection for reverse supply chain collaboration: A sustainable approach. Journal of Environmental Management, 236, 784-797.

Gregory, J. R., \& Kirchain, R. E. (2008). A framework for evaluating the economic performance of recycling systems: a case study of North American electronics recycling systems. Environmental Science \& Technology, 42(18), 6800-8.

Harris, J. (2000). Basic principles of sustainable development. Dimensions of Sustainable Development, 21-41.

Haryani, T., \& Subriadi, A.P. (2021). E-commerce acceptance in the dimension of sustainability. Journal of Modelling in Management. doi 10.1108/JM2-05-2020-0141. 
Holappa, L. (2020). A general vision for reduction of energy consumption and $\mathrm{CO} 2$ emissions from the steel industry. Metals, 10, 1117; doi:10.3390/met10091117.

Hu, J., Liu, Y., Yuen, T., Lim, M. \& Hu, J. (2019). Do green practices really attract customers? the sharing economy from the sustainable supply chain management perspective. Resources. Conservation and Recycling, 149, 177-187.

Hubbard, G. (2009). Measuring organizational performance: beyond the triple bottom line. Bus. Strateg. Environ. 18, 177-191.

Kaza, S., Yao, L., Bhada-Tata, P., \& Van Woerden, F. (2018). What a waste 2.0: a global snapshot of solid waste management to 2050. The World Bank. https://doi.org/10.1596/978-1-4648-1329-0.

Kurnaz, N., \& Kestane, A. (2016). Kurumsal sürdürülebilirliğin ekonomik açıdan incelenmesi ve yatırımcı davranışları ilişkisi: BİST sürdürülebilirlik endeksinde bir uygulama. Dumlupınar Üniversitesi Sosyal Bilimler Dergisi, 49, 278302.

Küçük, M., \& Güneş, G. (2013). Sivil toplum kuruluşları ve çevresel sürdürülebilirlik. Sosyal ve Beşeri Bilimler Dergisi, 5(2), 298-311.

Larsen, A. W., Merrild, H., \& Christensen, T. H. (2009). Recycling of glass: Accounting of greenhouse gases and global warming contributions. Waste Manag. Res., 27, 754762.

Lenort, R., Staš, D., Wicher, P., Holman, D., \& Ignatowicz, K. (2017). Comparative study of sustainable key performance indicators in metallurgical industry. Annual Set The Environment Protection, 19, 36-51.

McMichael, A. J., Butler, C. D., \& Folke, C. (2003). New visions for addressing sustainability. Science, (302), 19191920.

Ni, W., \& Sun, H. (2019). The effect of sustainable supply chain management on business performance: Implications for integrating the entire supply chain in the chinese manufacturing sector. Journal of Cleaner Production, 232, 1176-1186. doi: 10.1016/j.jclepro.2019.05.384.

Rao, P. (2002). Greening the supply chain: A new initiative in South East Asia. International Journal of Operations \& Production Management, 22(5), 631-655.

Rezaei, J. (2015). Best-Worst Multi-Criteria Decision-Making Method, Omega, 53, 49-57.

Santos, M. A. D., Svensson, G., \& Padin, C. (2013). Indicators of sustainable business practices: Woolworths in South Africa. Supply Chain Manag. Int. J., 18 (1), 104-108.

Shrivastava, P. (1995). The role of corporations in achieving ecological sustainability. Academy of Management Review, 20(4), 936-960.

Singh, R. K., Murty, H. R., Gupta, S. K., \& Dikshit, A. K. (2007). Development of composite sustainability performance index for steel industry. Ecol. Indicat., (7), 565588.

Spallini, S., Milone, V., Nisio, A., \& Romanazzi, P. (2021). The Dimension of Sustainability: A Comparative Analysis of Broadness of Information in Italian Companies. Sustainability 2021, 13(3), 1457; https://doi.org/10.3390/su13031457.

Sudharsan, N., Palanisamy, T., \& Subhash, C. Y. (2018). Environmental sustainability of waste glass as a valuable construction material-A critical review. Ecol. Environ. Conser., 24, 331-338.

Szekely, F., \& Knirsch, M. (2005). Responsible leadership and corporate social responsibility: metrics for sustainable performance. Eur. Manag. J., 23 (6), 628-647.

Tajbakhsh, A., \& Hassini, E. (2015). Performance Measurement of Sustainable Supply Chains: A Review and Research Questions. Int. J. Product. Perform. Manag., 64, 744-783.

Tsai, W., \& Hung, S. (2009). A fuzzy goal programming approach for green supply chain optimisation under activitybased costing and performance evaluation with a valuechain structure. International Journal of Production Research, 47 (18), 4991-5017.

Vachon, S., \& Mao, Z. (2008). Linking supply chain strength to sustainable development: a country-level analysis. J. Clean. Prod., 16 (15), 1552-1560.

Wang, Q., Li, J., Yan, H., \& Zhu, S. X. (2016). Optimal remanufacturing strategies in name-your-own-price auctions with limited capacity. Int. J. Production Economics, 181, 113-129.

World Steel Association. (2020). Steel facts. Erişim Tarihi: 1. 08. 2021, https://www.worldsteel.org/about-steel/steelfacts.html. 